\title{
FORMAÇÃO E SABERES DOCENTES NA EDUCAÇÃO PROFISSIONAL: UM RELATO DE EXPERIÊNCIA
}

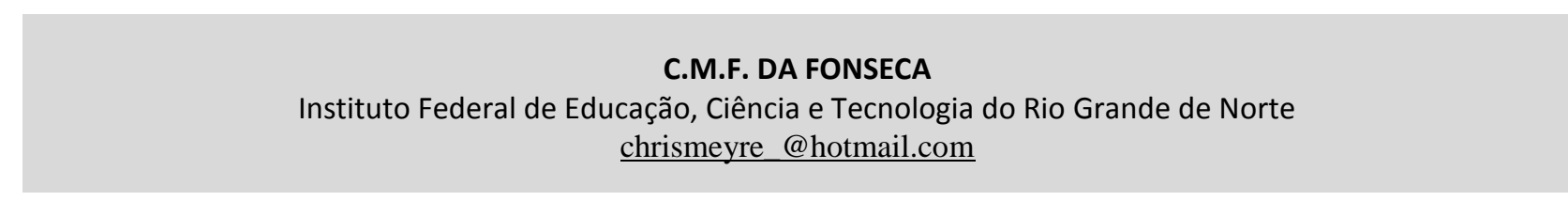

Artigo submetido em abril/2017 e aceito em maio/2017

DOI: $10.15628 /$ rbept.2017.5873

\section{RESUMO}

O presente artigo é o recorte de uma pesquisa maior intitulada "LICENCIADOS, BACHARÉIS E A FORMAÇÃO DOCENTE PARA ATUAR NA EDUCAÇÃO PROFISSIONAL E TECNOLÓGICA (EPT): um estudo com docentes do curso de informática no IFRN", que foi fruto de uma experiência realizada na disciplina Formação de Professores para Educação Profissional. A ideia partiu da necessidade de investigar a formação e as práticas pedagógicas de 27 professores que atuam no Ensino Médio Integrado (EMI) de Informática, nos diferentes núcleos do IFRN. A pesquisa se desenvolveu em três campi do IFRN investigando três categorias: identidade docente; prática pedagógica e percepção sobre EP. Sob essa perspectiva, sendo esta pesquisa um fragmento daquela, objetivamos analisar, a partir das concepções dos docentes do EMI de Informática, a necessidade de uma formação docente específica para atuar na educação profissional. Para tanto, desenvolvemos uma revisão bibliográfica articulada à pesquisa exploratória. Para a coleta de dados utilizamos a entrevista semiestruturada gravada. A pesquisa alicerçou-se em autores como: Moura (2008), Gadotti (2008), Souza (2013), Pimenta (2005), Tardif (2014), a partir dos quais traçamos discussões sob diferentes enfoques a respeito da formação docente e dos saberes necessários para atuar na educação profissional.

PALAVRAS-CHAVE: Formação docente, Saberes docentes, Educação Profissional

\section{TRAINING AND TEACHING KNOWLEDGE IN PROFESSIONAL EDUCATION: A REPORT OF EXPERIENCE}

\begin{abstract}
The present article is the cut of a larger research entitled "LICENSED, BACHELORS AND TEACHER TRAINING TO ACT IN PROFESSIONAL AND TECHNOLOGICAL EDUCATION (EFA): a study with teachers of the computer course at the IFRN", which was the result of an experience Discipline Teacher Training for Professional Education. The idea was based on the need to investigate the training and pedagogical practices of 27 teachers who work in the Integrated Higher Education of Informatics in the different IFRN nuclei. The research was developed in three campuses of the IFRN investigating three categories: teacher identity; Pedagogical practice and perception about PE. From this
\end{abstract}

perspective, since this research is a fragment of this, we aim to analyze, from the conceptions of the teachers of the Informatics Integrated Higher Education, the need for a specific teacher training to work in professional education. For this, we developed an articulated bibliographical review of the exploratory research. For the collection of data we used the semi-structured interview recorded. The research was based on authors such as: Moura (2008), Gadotti (2008), Souza (2013), Pimenta (2005), Tardif (2014), from which we drew discussions under different approaches regarding teacher education and Knowledge needed to work in professional education.

KEYWORDS: Teacher training, Teaching skills, Professional education. 


\section{INTRODUÇÃO}

O presente artigo é um recorte de uma pesquisa maior intitulada "LICENCIADOS, BACHARÉIS E A FORMAÇÃO DOCENTE PARA ATUAR NA EDUCAÇÃO PROFISSIONAL E TECNOLÓGICA (EPT): um estudo com docentes do curso de informática no IFRN", a qual buscou investigar quem são os docentes da EP no IFRN, qual a sua percepção sobre a EPT e como eles percebem a sua formação e sua prática pedagógica.

A pesquisa buscou analisar a formação e as práticas pedagógicas de 27 professores do Ensino Médio Integrado de Informática, dos núcleos estruturante, articulador e tecnológico constantes no projeto dos cursos técnicos de nível médio do IFRN. A pesquisa foi realizada em três campi - Natal Central, Natal Zona Norte e Parnamirim - por meio de entrevista a 9 (nove) professores de cada campi, investigando três categorias: identidade docente; prática pedagógica e percepção sobre EP.

Dessa pesquisa supracitada, surge esta, circunscrita à categoria identidade docente e intitulada FORMAÇÃO E SABERES DOCENTES NA EDUCAÇÃO PROFISSIONAL: UM RELATO DE EXPERIÊNCIA, sobre a qual limitamos nossos estudos, tendo como objetivo analisar, a partir das concepções dos docentes do EMI (Ensino Médio Integrado) de Informática, a necessidade de uma formação docente específica para atuar na educação profissional.

Para tanto, desenvolvemos o tema proposto por meio de revisão bibliográfica, articulada a uma pesquisa exploratória, cujos dados foram buscados na investigação empírica. Como instrumento de coleta de dados utilizamos a entrevista semiestruturada com os docentes, sujeitos da pesquisa.

Para melhor localizar o leitor, deixamos claro que o artigo estrutura-se em três seções: na primeira buscamos apresentar o perfil do profissional que atua na educação profissional (EP) e as especificidades de sua formação; na segunda, discutimos sobre os saberes docentes necessários para a EP; e, por último, expomos nossas considerações finais apresentando nossas reflexões acerca do que foi analisado durante a pesquisa.

No que se refere ao referencial teórico, o trabalho alicerçou-se em autores como Moura (2008), Gadotti (2008), Souza (2013), Pimenta (2005), Tardif (2014), a partir dos quais traçamos discussões sob diferentes enfoques a respeito da formação docente e dos saberes necessários para atuar na educação profissional. 
Desse modo, a ideia é contribuir para um debate teórico, a partir de uma análise prática, a fim de explorar as necessidades inerentes à atuação docente na Educação Profissional Tecnológica (EPT).

\section{FORMAÇÃO DOCENTE PARA ATUAR NA EDUCAÇÃO PROFISSIONAL}

Nos dias atuais, são atribuídos diferentes e novos papéis ao professor, é o que Gadotti (2008) chama de uma nova cultura profissional, na qual as instituições e a concepção do papel docente se redefinem.

Para tanto, faz-se necessário compreender esses novos papéis, entendendo como estes se desdobram diante das diferentes características em que os sistemas de ensino se constituem. 0 IFRN, por exemplo, é uma instituição que oferta uma educação de nível médio integrada a EPT. E que, para isto, deve ter uma sólida concepção de educação profissional, e seus profissionais devem ou, pelo menos, deveriam estar preparados para atuar e atender à demanda a ela exigida.

Mas afinal, é necessária uma formação específica para atuar na EP? Será esta necessária para atuação docente? Muitos são os questionamentos que permeiam as reflexões acerca da formação docente para a educação profissional, contudo, consideraremos estes como norte de nossa pesquisa.

Formação docente é uma temática complexa de ser discutida e, quando a vinculamos ao âmbito da EPT, ela se torna ainda mais complexa, porque está ligada à diversa formação profissional - licenciados, bacharéis, técnico, tecnólogo. Nesse sentido, é preciso considerar a especificidade de cada formação, e consequentemente, de cada profissional, para discutir a formação docente necessária para atuar na EPT.

Não podemos considerar que a formação para licenciados é a mesma ofertada para os bacharéis, nem tampouco para os técnicos, bem como, não podemos assegurar que a atuação desses profissionais, no âmbito educacional, será a mesma, uma vez que existem peculiaridades na formação e na atuação docente. Não podemos julgar que a aula de um profissional será mais satisfatória que a outra. Mesmo porque, isso dependerá dos saberes provenientes e internalizados na formação individual, da experiência de vida e das experiências profissionais de cada responsável.

Sendo assim, ao se tratar de atuação docente, faz-se necessário que este, para o cumprimento de sua função entenda qual a função social e que tipo de educação é defendida e ofertada pela instituição. Nesse caso, se a instituição ofertar a Educação Profissional e 
Tecnológica, é imprescindível entender as responsabilidades definida pelo campo da educação profissional, especificamente, da instituição, para que se possam encontrar possibilidades de atuação no processo educativo. Para tanto, o docente também pode e deve buscar outras formações em consonância com o campo de atuação profissional.

Assim, acreditamos que todos os profissionais - docentes, técnicos-administrativos e dirigentes de instituições da EPT - devem ser bem qualificados e profissionalmente formados. E quando falamos em qualificação e formação, não é apenas em seu sentido estrito, mas também em seu sentido amplo. Sob essa perspectiva, Moura (2008, p.30) destaca:

o objetivo macro é mais ambicioso e deve privilegiar a formação no âmbito das políticas públicas do país, principalmente as educacionais, numa perspectiva de superação do modelo de desenvolvimento socioeconômico vigente, de modo que se deve priorizar mais o ser humano do que, simplesmente, as relações de mercado e o fortalecimento da economia.

Essa visão ampla de formação possibilita aos professores, irem além da mera técnica do saber ensinar os conteúdos (transposição didática), e aos dirigentes, as técnicas de gestão, contribuindo, desse modo, para transpor os limites da educação bancária, denominada por Paulo Freire, formando indivíduos autônomos e transformadores de seu meio.

Mas para ultrapassar esses limites de uma educação memorística e tradicional, devemos entender que a,

A formação para a emancipação requer uma profunda interação teórico-prática, uma visão de totalidade, uma prática de interdisciplinaridade, bem como a efetiva capacidade de orientação/interpretação dialética da realidade. (SOUZA, 2013, p. 393).

Assim, para possibilitar a mudança e alcançar essas metas supracitadas, é preciso atentar no contexto da formação docente na educação profissional, a articulação entre a dimensão técnica e a dimensão humana. Sob essa ideia, Moura (2008) define a formação dos docentes em dois grandes eixos - um refere-se à área específica do conhecimento, aquela adquirida na graduação e em outros níveis maiores de ensino; o outro concerne à formação didático-político pedagógica e às especificidades inerentes ao âmbito da EPT.

Esta ideia nos leva a refletir sobre um momento da aplicação do questionário, ao perguntar a um professor que compõe o núcleo estruturante do campus de Parnamirim, se o ele acreditava ser necessária uma formação específica para a Educação Profissional. Ele argumenta:

[...] com certeza, eu não vou saber agora dizer... argumentar sobre o porquê, na verdade a minha aula de geografia na EP é a igual a, é a mesma grade... 
entendeu? Eu nunca trabalhei com geografia voltada para a educação profissional. Porque é a mesma grade, né... mas com certeza. Principalmente os professores que dão aula de disciplinas técnicas, eles devem ter isso aí com mais cuidado ainda. Mas minha aula de geografia não mudou nada.

Outro professor entrevistado, dessa vez do núcleo estruturante do IFRN - Zona Norte, sobre essa mesma questão, afirma que:

Sim. Aí é mais do que necessária. É um calo que a Educação Profissional tem que resolver. Não basta contratar professores. A gente tem que entender que há umas articulações de formação e atuação profissional nessa área. Então, como a gente não consegue articular as condições via Universidade (que não é uma tarefa assim tão fácil, né, rápida e objetiva), a gente precisa dentro da Educação Profissional Técnica e Tecnológica, SETEC/MEC, né, os Institutos firmarem esse compromisso. Eu acho que é uma pauta a ser seguida: formação específica para quem está atuando na Educação Profissional.

Por meio dessas concepções dos professores, percebemos claramente a necessidade de formação docente para a educação profissional e tecnológica. O primeiro professor destaca que nunca trabalhou a geografia, sua disciplina de ensino, articulada à educação profissional. O outro entende que existe uma articulação entre sua formação e a educação profissional, mas que na Universidade não foram dadas condições para esse entendimento, então, cabe aos Institutos firmarem um compromisso com esse campo.

Diante do quadro apresentado, poderíamos dizer que o IFRN urge por um momento de formação, na qual se articule formação específica e formação geral. Mas não somente um momento fragmentado de capacitação, e sim, um que integre formação contínua de troca de conhecimentos e reflexão sobre a prática dos docentes. Por outro lado, consideramos fundamental que essa formação também seja iniciativa do próprio profissional.

Ora, se a função do IFRN é formar cidadãos sob uma perspectiva onmilateral e de formação humana integral, pensando nessa perspectiva, deveria ofertar formações pensando nas melhorias que estas podem trazer aos seus profissionais. Em contrapartida, se o professor apresenta dificuldade em trabalhar sob a concepção que o IFRN exige, é preciso que busquem saberes necessários para atuar na EPT, e atender as exigências institucionais. Logo, a formação docente deve ser pensada em consonância com a função social da instituição de ensino e a insuficiência da prática integrada à educação profissional. 


\section{SABERES DOCENTES NA EDUCAÇÃO PROFISSIONAL}

O cenário caracterizado anteriormente, sobre a necessidade de formação docente para atuar na educação profissional, nos leva a outro questionamento: considerando o panorama discutido sobre a necessidade de uma formação docente específica para atuar EPT, que saberes docentes são necessários nessa modalidade de ensino?

Considerando que a formação docente para a EPT pode ser vista a partir das necessidades de vários segmentos - licenciados, bacharéis, técnico, tecnólogo - e daqueles que estão em processo de formação e considerando também que cada um desses profissionais têm uma formação com especificidades singulares, deduzimos que essas mesmas peculiaridades devem ser levadas em consideração em relação à ação docente e à formação para atuar na educação profissional, as quais exigem saberes necessários e específicos a cada situação.

Nesse sentido, defendemos que os saberes docentes, independentemente da singularidade na formação inicial, são oriundos de ambientes diferenciados tais como: saberes construídos das experiências de vida, saberes escolares e saberes adquiridos na prática docente, os quais Tardif (2014) denomina como: saberes pessoais, saberes provenientes da formação profissional para o magistério, saberes provenientes da formação escolar anterior, e ainda, os saberes provenientes dos programas e livros didáticos usados no trabalho. Entre os segmentos que podem trabalhar na EPT, apenas os licenciados têm, em sua formação inicial, acesso ao saber da formação profissional para o magistério.

No caso dos professores que atuam na educação profissional tecnológica percebemos uma lacuna dos saberes provenientes nessa esfera, principalmente no que se refere a - como articular os conhecimentos gerais aos específicos, seja em qualquer âmbito em que o saber se constitui. Sob esta ótica uma professora entrevistada, do núcleo estruturante do IFRN - Natal Central, ao ser questionada se é necessária uma formação para EP, aponta:

Bem, eu especificamente a aqui na na no instituto federal quando eu (aceitei) por meio de concurso era CEFET éé eu comecei a trabalhar em cursos técnicos na área de alimentos e de informática eee e inicialmente eu, eu tive assim uma certa dificuldade de de compreender aquele universo, mas o dia a dia é.. foi me ensinando a a a lidar com jovens de cursos diferentes. 
Sobre essa afirmação, conseguimos constatar uma dificuldade concreta encontrada pela professora em atuar na educação profissional. Contudo, o seu saber construído na prática, por meio de sua experiência docente, foi-lhe permitindo encontrar novos caminhos e dar continuidade ao processo educativo.

A respeito dos saberes experienciais, Pimenta (2005) afirma que eles nascem da experiência acumulada no espaço da docência de cada professor com a prática, com o intuito de superar os problemas cotidianos. Posto isto, podemos considerar que,

A relação dos docentes com os saberes não se reduz a uma função de transmissão dos conhecimentos já constituídos. Sua prática integra diferentes saberes, com os quais o corpo docente mantém diferentes relações. Pode-se definir o saber docente como um saber plural, formado pelo amálgama, mais ou menos coerente, de saberes oriundos da formação profissional e de saberes disciplinares, curriculares e experimentais. (TARDIF, 2014, P. 36).

Assim, na ação docente não se faz necessário apenas os saberes da disciplina que se leciona, que se refere ao domínio dos conteúdos, é preciso também, articular os conhecimentos advindos das experiências de vida e da prática profissional. E é justamente neste último que o professor se depara com as dificuldades relacionadas à sua prática e, devem procurar meios para saná-las.

Desse modo, nada melhor que refletir sobre a prática a partir de formações contínuas, visando entender os saberes necessários para atuar na educação profissional. Essas formações por sua vez, devem ser buscadas pelo próprio docente, impulsionada pela instituição, nesse caso, o IFRN, que é o locus de atuação dos professores entrevistados.

No que tange ainda aos saberes necessários à prática docente, PIMENTA (2005, p.8) ressalta que

O saber do professor se fundamenta na tríade saberes das áreas específicas, saberes pedagógicos e saberes da experiência. É na mobilização dessa tríade que os professores desenvolvem a capacidade de investigar a própria atividade e, a partir dela, constituírem e transformarem seus saberes-fazeres docentes.

Sendo assim, de acordo com a fala dos docentes, no transcorrer da pesquisa, inferimos que o professor que atua na EP tem sua prática dificultada, por, na maioria das vezes, não 
conseguir articular conhecimentos gerais e específicos à educação profissional e, possivelmente, por não entender quais os saberes necessários para atuação na EP, além de dar mais importância a um saber que outro, quando na verdade, estes saberes devem estar associados às diferentes áreas, impulsionados por sua ação-reflexão-ação.

Nesse sentido, acreditamos que é imprescindível mobilizar os diferentes saberes apresentados até então, levando em consideração a especificidade da formação (inicial licenciatura, bacharelado, técnico e tecnólogo; ou continuada), e da instituição, refletindo continuamente sobre sua prática e buscando sanar dificuldades encontradas diante da sua atuação docente.

Portanto, o professor é o elemento primordial e responsável por sua transformação e conscientização, o sujeito que pensa e repensa, visando mudar sua prática de ensino, por meio da mobilização dos saberes provenientes das mais variadas esferas.

\section{CONSIDERAÇÕES FINAIS}

A análise dessa temática colocou em evidência, ao longo da pesquisa, que é necessário buscar uma nova proposta de formação docente na educação profissional para os professores que atuam no IFRN, pois estes mostram, por meio de suas falas, que encontram obstáculos na prática docente para atuar nessa modalidade de ensino. Uns acreditam que é necessária uma formação para aqueles de áreas específicas, outros afirmam que essa formação é necessária a todos os profissionais que atuam como docente em instituições que atuam na EP.

$\mathrm{Na}$ verdade, acreditamos nesta última premissa. O IFRN como instituição que oferta educação profissional precisa fortalecer sua concepção de ensino voltada a esse campo de ensino. Dessa forma, (re)pensar a formação de todos os seus profissionais, pois estes, na sua maioria, ao chegarem no instituto demonstram dificuldades em articular os saberes gerais aos específicos para a EPT. Talvez por, na sua grande parte, não terem formação específica em EP ou por sua formação ter deixado lacunas que não os permitiram entender a estreita relação com o mundo do trabalho.

Para tanto, é preciso apresentar a esses profissionais o estreito relacionamento entre o contexto de sua formação específica e os saberes elencados como necessários à prática docente na EP. Momentos em que se reflita sobre a prática docente, pois é, por meio desse entendimento, que será possível minimizar as dificuldades encontradas no espaço da docência. 
Dessa forma, acreditamos que cabe ao professor buscar formação necessária a sua prática, impulsionados pela instituição que também necessita de profissionais capacitados na área, para, então, ofertar uma educação de qualidade.

Sendo assim, é necessário uma formação e saberes específicos para atuar na educação profissional, para que possamos entendê-la não como um simples instrumento de política assistencialista ajustados às demandas do mercado de trabalho, e, sim, como importante estratégia para que os cidadãos tenham efetivo acesso às conquistas científicas e tecnológicas vigente na sociedade.

Portanto, os IFRN's devem reafirmar sua concepção de ensino articulado à educação profissional, por meio de formações contínuas que visam refletir sobre a prática docente, nas quais os docentes possam desenvolver os diferentes saberes necessários à prática para a educação profissional e concretizar um ensino de qualidade, voltados para uma formação humana integral.

\section{REFERÊNCIAS}

1. GADOTTI, Moacir. Boniteza de um sonho: ensinar-e-aprender com sentido. São Paulo: Ed,L, 2008.

2. PIMENTA, S. G. Formação de Professores: identidade e saberes da docência. In: PIMENTA, S. G. (Org.) Saberes pedagógicos e atividade docente. São Paulo (SP): Cortez, 2005.

3. REVISTA BRASILEIRA DA EDUCAÇÃO PROFISSIONAL E TECNOLÓGICA. Campinas, v. 1, n. 1, 2008. Disponível em: <http://www2.ifrn.edu.br/ojs/index.php/RBEP/search/search>. Acesso em: 05. out. 2015.

4. SOUZA, Antonio Lisboa Leitão de. Formação inicial e continuada de professores para a educação profissional: a política e a produção do conhecimento para a emancipação. In: MOURA, Dante Henrique. Produção do conhecimento, políticas públicas e formação docente em educação profissional. São Paulo: Mercado das letras, 2013, p. 385-407.

5. TARDIF, Maurice. Saberes docentes e formação profissional. 16 ed. Vozes, RJ: 2014. 